\title{
EL CASO DEL ESCRITOR PEDRO CASTERA: ENTRE LA ESFERA PÚBLICA, EL CAMPO LITERARIO Y LA EXPERIENCIA MANICOMIAL EN EL MÉXICO DE FINALES DEL SIGLO XIX
}

\author{
José Antonio Maya González \\ Universidad Autónoma Metropolitana, unidad Xochimilco \\ Email: jomayago@gmail.com \\ ORCID iD: http://orcid.org/0000-0001-9840-2179 \\ Ana Laura Zavala Díaz \\ Instituto de Investigaciones Filológicas, Universidad Nacional Autónoma de México, \\ Ciudad de México \\ Email: alzavalad@yahoo.com \\ ORCID iD: http://orcid.org/0000-0003-0883-7334
}

Recibido: 24 abril 2018; Aceptado: 26 febrero 2019.

Cómo citar este artículo/Citation: Maya González, José Antonio / Zavala Díaz, Ana Laura (2019), "El caso del escritor Pedro Castera: entre la esfera pública, el campo literario y la experiencia manicomial en el México de finales del siglo XIX", Asclepio, 71(2): p280. https://doi.org/10.3989/asclepio.2019.21

RESUMEN: En el verano de 1883, el escritor, minero, científico y seguidor del espiritismo Pedro Castera (1846-1906) fue recluido en el Hospital de San Hipólito para hombres dementes de la Ciudad de México. El confinamiento y la situación de aislamiento del también poeta despertó acalorados debates y disputas sobre su condición mental. Los motivos de su internamiento y las conjeturas acerca de la psicopatología que lo aquejaba fueron cruciales dentro de la narrativa de este caso, en el que convergieron intrigas políticas, sospechas familiares, controversias médicas y convenciones literarias. El objetivo del presente trabajo es analizar las valoraciones médicas alrededor de la reclusión, permanencia y salida de Pedro Castera del nosocomio, con el fin de reflexionar, asimismo, en torno a la resignificación de la figura del loco-literario, a partir de la emergencia del discurso de la medicina mental en el contexto de la modernidad mexicana en el último tercio del siglo XIX.

PALABRAS CLAVE: Locura; Psiquiatría; Literatura; Confinamiento; Porfiriato

THE CASE OF THE WRITER PEDRO CASTERA: BETWEEN THE PUBLIC SPHERE, THE LITERARY FIELD AND THE MENTAL HOSPITAL EXPERIENCE IN MEXICO AT THE END OF THE XIX CENTURY

ABSTRACT: In the summer of 1883, the writer, miner, scientist and follower of spiritism Pedro Castera (1846-1906) was detained at the Hospital de San Hipólito for demented men in Mexico City. The confinement and isolation of the also poet aroused heated debates and disputes surrounding his mental condition. The reasons for his internment and the conjectures about the psychopathology that afflicted him were crucial within the narrative of a case in which political intrigues, family suspicions, medical controversies and literary conventions converged. The aim of the present work is to analyze the medical valuations around the confinement, permanence and exit of Pedro Castera in and from the hospital, as well as to reflect on the resignification of the figure of the literary-madman from the emergence of the discourse of mental medicine in the context of Porfirian modernity.

KEY WORDS: Madness; Psychiatry; Literature; Confinement; Porfiriato

Copyright: (C) 2019 CSIC. Este es un artículo de acceso abierto distribuido bajo los términos de la licencia de uso y distribución Creative Commons Reconocimiento 4.0 Internacional (CC BY 4.0). 


\section{INTRODUCCIÓN}

En el verano de 1883, la prensa de la Ciudad de México informó a sus lectores que el escritor, minero, científico autodidacta y seguidor del espiritismo Pedro Castera (1846-1906) había sido recluido en el Hospital de San Hipólito para hombres dementes. El periódico liberal El Siglo Diez y Nueve notificó que el también poeta fue trasladado al nosocomio junto con el médico Agustín Galindo ${ }^{1}$, lo que despertó múltiples interrogantes acerca de la condición mental de tan connotados personajes: "Algo siniestro rodea la existencia de los hombres de algún valor, cuando así tenemos que registrar dos desgracias semejantes en tan pocos días"2.

Un año antes, Castera había logrado el reconocimiento literario con Carmen. Memorias de un corazón, debido a la buena recepción que tuvo la novela entre los lectores de la época ${ }^{3}$, diversos medios pronto anunciaron el "sobretiro" de ejemplares que podían adquirirse en la redacción del diario La Repúbli$c a^{4}$. Con la aparición de los libros Las minas y los mineros, Los maduros, Ensueños y armonías e Impresiones y recuerdos, publicados también en 1882, el narrador estaba llamado a consagrarse en el panteón de los hombres ilustres, pero una serie de infortunados acontecimientos truncaron su prolífica producción que devino en cierto ostracismo en los últimos años de su vida, según testimonió el poeta Rubén M. Campos (1876-1945): "va Castera errante, con su corpachón de hombrazo hercúleo vestido al uso de su tiempo, con un gran sombrero plano y una capa española azul clara, sin saludar a nadie y sin que nadie lo salude a él" (2013, p. 57). Para principios del siglo $x x$, el escritor era uno más de aquellos talentos "rezagados de la generación literaria", un "viejo novelista" tan popular y olvidado como la novela misma que alguna vez escribió (Campos, 2013, p. 57). Enfermo, y quizá desdeñado por algunos literatos "modernos", murió en el pueblo de Tacubaya en 1906.

Aun cuando la historiografía y los estudios literarios de las últimas décadas han recuperado el valor filológico y cultural de la obra casteriana, sólo han examinado desde lo anecdótico el episodio en San Hipólito. En el "Prólogo" a Carmen. Memorias de un corazón de 1950, el reconocido crítico literario Carlos González Peña dejó entrever la posibilidad de que Castera hubiera sido confinado por negarse a realizar una campaña gubernamental en favor de la moneda de níquel en 1882 (1950, pp. 15-16). Tal ruta interpretativa pro- pició, décadas más tarde, la mitificación de la conspiración política que detalló el historiador Antonio Saborit en un artículo escrito para la revista Nexos (1987). Más adelante, abordaremos algunos aspectos de la campaña monedera impulsada por el entonces presidente Manuel González. Por su parte, en la introducción a la obra Las minas y los mineros, el investigador Luis Mario Schneider afirmó que el trabajo excesivo, las actividades múltiples y la febril producción del narrador y poeta "tuvieron indudablemente que conducirlo a una crisis mental" (1987, p. 15). Recientemente, Dulce María Adame, en su "Estudio preliminar" a la edición crítica de Ensueños y armonías, refirió al litigio que enfrentó el escritor por unas tierras en Michoacán (Adame, 2015, pp. 38-42), lo que ha permitido considerar la figura legal del "juicio de interdicción" como otro de los derroteros de análisis para entender el proceso de su reclusión.

Si bien estos trabajos muestran diferentes miradas sobre el confinamiento manicomial de Pedro Castera, no logran explicar en profundidad cuál fue el contexto médico-legal que posibilitó su encierro, ni las consecuencias que esto trajo tanto para Castera como para el campo literario de su momento. Una revisión de la prensa de la época ayuda a comprender que el ingreso y la situación de aislamiento del poeta despertó acalorados debates, tensiones y disputas acerca de su condición mental. Algunos médicos y funcionarios afirmaron que se trataba de un "enajenado peligroso" que podía atentar contra la sociedad; en cambio, colegas, amigos y familiares veían en Castera al infortunado escritor, víctima de soterradas conspiraciones y profusos sentimentalismos. Los motivos de su internamiento y las conjeturas sobre la psicopatología que lo aquejaba fueron cruciales dentro de la narrativa de un caso en el que convergieron intrigas políticas, sospechas familiares, controversias médicas y convenciones literarias, las cuales merecen un examen más profundo a partir de la investigación en las fuentes periodísticas de aquel momento.

El objetivo del presente trabajo es analizar las valoraciones médicas alrededor del confinamiento y permanencia de Pedro Castera en San Hipólito, para reflexionar en torno a la conformación de la figura del loco-literario a la luz de la emergencia del discurso de la medicina mental en el México porfiriano. Argumentamos que, si bien su corta estancia hospitalaria lo condenó a la inhabilitación política debido al estigma de la locura, en el ámbito literario logró darle prestigio, en la medida que configuró su imagen como 
la de un genio creador enajenado por el "dolor de la producción" (Zavala, 2012, pp. 60-61), asunto ampliamente debatido en esos años. Su representación como héroe romántico en desgracia contribuyó a granjearle un reconocimiento simbólico y económico, el cual incidió tanto en su re-posicionamiento en el contexto literario como en la revaloración de su narrativa, en un ambiente editorial y social marcado por las fuertes tensiones, producto del desigual proceso de modernización que experimentó México en las últimas décadas del siglo XIX. Este trabajo se inscribe entre la historia cultural de la psiquiatría y la historia de las ideas y de los estudios literarios, enfoques desde los que nos interesa meditar acerca de las actitudes colectivas que dieron forma a "elaboraciones culturales" (Huertas, 2012, p. 12) sobre la peligrosidad del genio y de la locura. Para ello, hemos recurrido a fuentes diversas: desde diagnósticos médicos hasta crónicas parlamentarias y literarias, cartas, reportajes, poemas y novelas, publicados en los principales diarios. En este sentido, cabe subrayar que la prensa decimonónica en México fue un medio de comunicación en suma politizado, que permitió la circulación de noticias entre el público lector y la sociedad, así como el posicionamiento de ideas, proyectos y posturas divergentes que ayudaron a la construcción de la opinión pública (Gantús y Salmerón, 2014, pp. 12, 14; Piccato, 2005). Desde ese espacio de enunciación, el confinamiento de Pedro Castera en el hospital para dementes suscitó discursos ambivalentes, sobre todo por tratarse de un famoso letrado escindido entre la locura y la genialidad.

\section{"VÍctima de LA MÁs NegRA de LAS fatALIDADES..."}

"Al manicomio se va por muchos caminos", advirtió un articulista de El Monitor Republicano en 1882, entre los cuales estaban "la lucha violenta de las pasiones", así como "la felicidad inesperada, la ambición desmedida, el eterno soñar y el amor impetuoso" ${ }^{\prime 5}$. Esta observación sugiere que los comportamientos exagerados y las actitudes pasionales eran valoraciones sociales de gran importancia que los propios médicos avalaron con sus investigaciones. Para los facultativos interesados en las cuestiones mentales durante el último tercio del siglo XIX, el estudio de las psicopatías representaba un asunto de relevancia científica y cultural: primero, porque, desde una perspectiva global y local, se consideraban enfermedades biológico-cerebrales; segundo, porque los "locos" eran percibidos como sujetos pasionales alejados del ideal de ciudadano libre y jurídicamente responsable que se quería imponer desde el Estado (Sacristán, 2002, pp. 65-66). Muchos galenos porfirianos coincidieron en una visión organicista, según la cual los padecimientos mentales estaban determinados por disfunciones del sistema nervioso y de la médula espinal (Ríos, 2009, p. 95). Sin embargo, tanto en sus discursos como en sus prácticas, fueron bastante eclécticos para explicar sus causas, debido a que apelaron a lo psicológico, lo orgánico y lo social, pero también relacionaron dichos malestares con la marcha irreversible de la civilización, en un contexto claramente marcado por una incipiente modernización ideológica y material en el país.

Durante el Porfiriato (1876-1911) tuciones destinadas a la atención de personas con alguna enfermedad mental: el Hospital del Divino Salvador (1700) para mujeres y el de San Hipólito (1566) para hombres, que se establecieron durante el Virreinato y que, a partir de 1877, dependieron de la Dirección General de la Beneficencia Pública, instancia fundada por el gobierno de Díaz en ese año. Ambos nosocomios fueron espacios para la atencióncontención de los locos, donde se fusionó la práctica médica con el trato compasivo de inspiración clerical. En ellos se confinó a toda clase de pacientes: alcohólicos, criminales y una multitud de individuos transgresores que fueron considerados por sus familias y/o su entorno social como merecedores de encierro (Sacristán, 1998, p. 208; Ríos, 2008). Aun cuando en esta época no existió un proyecto alienista fincado en la consolidación de un gremio y en el desarrollo de la investigación en México (Ríos, 2016, pp. 20, 23), sí hubo experiencias hospitalarias realizadas por galenos preocupados por la enfermedad mental, la marginación y las actividades viciosas de los sectores populares (Villa, 2008; Ramos, 2015, pp. 265-288; Maya, 2015). Es evidente que, pese a la voluntad de los facultativos de sondear los territorios de la locura, lejos estaban de constituir una medicina psicopatológica preparada para establecer con claridad los límites entre la cordura y la sinrazón. En este contexto de incertidumbre clínica y de atención/contención hospitalaria, pero también de creciente interés médico y social por esos padecimientos, se inserta el proceso de reclusión de Castera.

El $1^{\circ}$ de enero de 1882 , el novelista asumió la dirección de La República. Periódico Político y Literario en sucesión del escritor Ignacio Manuel Altamirano 
(1834-1893) ${ }^{7}$. Luego de seis meses al frente del diario, renunció a su cargo para atender "negocios importantes" que lo obligaron a salir de la Ciudad de México. En su columna de despedida, Castera agradeció a sus amigos del semanario y, en particular, reconoció al entonces presidente González (1880-1884) como "dignísimo general", a quien entregaría sus "esfuerzos por contrariar los ataques de sus enemigos y a poner de relieve las patriotas y elevadas miras del ilustre jefe de la Nación" ${ }^{\prime 8}$. De manera sorpresiva, para junio de 1883, su nombre apareció en la lista de pensionistas del Hospital de San Hipólito, donde permaneció recluido hasta mediados del mes de diciembre de 1884 , aproximadamente ${ }^{9}$. Las primeras estadísticas de la locura indican que, entre 1867 y 1886, el establecimiento albergó 1,632 pacientes. En este periodo, los asilados en el departamento de indigentes representaron más de la mitad de la población confinada, mientras que los pensionistas conformaron una tercera parte (Ramos, 2015, pp. 275-277). De acuerdo con la información consignada en el expediente, Castera ingresó en calidad de pensionista, por lo tanto, debía pagar doce pesos mensuales para gastos de manutención; sin embargo, poco tiempo después, sus conocidos más cercanos confirmaron que el poeta no contaba con recursos financieros dentro del inmueble.

Según se advirtió, su encierro, permanencia y salida atraparon la atención de los capitalinos no sólo por tratarse de un funcionario que, al momento de su internamiento, ocupaba una silla como suplente en el Congreso de Puebla, sino también por las extraordinarias confabulaciones y suspicacias que suscitó la historia del poeta abatido ${ }^{10}$. Algunos amigos que participaron en la prensa política de la capital observaron con preocupación el comportamiento de su compañero de letras. Por ejemplo, el médico, escritor y periodista Salvador Quevedo y Zubieta (1856-1935) afirmó, en su libro Manuel González y su gobierno (Quevedo y Zubieta, 1885), que Pedro Castera "se volvió loco" en el contexto de la "empresa monedera”, y aseguró que gritaba en San Hipólito: “iQuiero níquel! iTráiganme más níquel!” (1885, p. 148). Quevedo, sin embargo, nunca mencionó que el entonces presidente González lo hubiera mandado recluir por insubordinación ${ }^{11}$.

La aparente obsesión por el aludido metal permitió urdir en el imaginario de los testigos una narrativa que, presuntamente, vinculaba el contexto político y económico del momento con la locura del autor. En efecto, el 23 de abril de 1881, el entonces presidente Manuel González presentó un proyecto de ley destinado a la acuñación de una nueva moneda de cobre y níquel, en sustitución de la de plata que había dominado en la escena nacional desde la Colonia. En diciembre, el Congreso aprobó la emisión, pero la enorme cantidad de monedas puestas en circulación, su valor inferior al nominal y la actitud gubernamental que sólo las admitía en cantidades limitadas, condujeron a su depreciación, lo cual desató movilizaciones callejeras que desembocaron en el célebre motín del 21 de diciembre de 1883 (Gutiérrez, 2013), que terminó controlando la administración gonzalista ${ }^{12}$.

Bajo tales condiciones, el 27 de octubre de 1883, una pequeña comitiva, encabezada por los periodistas Marqués d'Equevilley, Adolfo Carrillo y el aludido Quevedo y Zubieta, visitó a Castera con el fin de abogar en favor de su "hermano de letras". De acuerdo con su testimonio, el escritor se encontraba en un estado deplorable, por lo que le ofrecieron algo de dinero para sus gastos, a lo cual éste respondió: "usted se burla... eso no es níquel, es despreciable y vil plata". El entonces director de San Hipólito, Juan Govantes, informó a los acompañantes que el paciente padecía "monomanía del níquel", diagnóstico que, aun cuando no esclarecía las razones de su internamiento, sí formulaba una primera explicación "científica" acerca de su comportamiento anormal ${ }^{13}$.

Según varios autores (Foucault, 1976; Campos, Martínez, Huertas, 2000), la monomanía fue un concepto del alienismo francés, surgido en la primera mitad del siglo XIX; se trataba de una forma de locura en la que el individuo razonaba como cualquier otro, excepto porque deliraba sobre un objeto o un círculo limitado de ideas. En México, la monomanía no tuvo una amplia recepción en los terrenos de la medicina mental. Si bien algunos facultativos lo aceptaron, otros criticaron fuertemente dicho diagnóstico, porque mediante su uso se pensaba que una persona podía evadir la justicia (Sacristán, 2016) ${ }^{14}$. No obstante que esta noción perdió validez en Europa hacia finales de la década de 1870 a consecuencia de las críticas recibidas en Francia, el dictamen de Govantes apuntaba hacia la pervivencia de tal categoría clínica, posiblemente en el marco de la reflexión y el estudio de las llamadas locuras parciales o razonantes, cuya discusión estuvo vigente hasta principios del siglo $X^{15}$. Difundido de forma masiva por los periódicos, ese diagnóstico forjó en la mente de los lectores del momento la idea del escritor delirante, obsesionado 
por el níquel, y, en la de los críticos contemporáneos (Saborit, 1987), la historia de uno de los primeros personajes connotados en sufrir represión política por parte de los gobiernos emanados del Plan de Tuxtepec, práctica que se volvería recurrente durante la larga dictadura de Díaz.

De noviembre de 1883 a finales de mayo de 1884 , el caso Castera tuvo una menor cobertura periodística; el 3 de febrero de 1884, por ejemplo, en una extensa crónica, el también poeta Agustín F. Cuenca narró su encuentro con el escritor en la Alameda acompañado por el director del nosocomio y su apoderado legal-, a propósito del cual sentenció con notable pesadumbre: "Para nosotros, San Hipólito era el sepulcro de Castera" ${ }^{16}$. Esta representación del confinamiento manicomial familiarizó al público lector con algunas ideas médicas, de acuerdo con las que el encierro hospitalario del hombre público significaba su muerte como ciudadano, pues, como quedó claro en aquellas notas, desde el punto de vista jurídico, médico y social, ser declarado loco equivalía a una muerte civil; por ello, el inculpado se convertía en sujeto de tutela y era despojado de sus derechos constitucionales.

Unos meses después, el 27 de mayo, otro grupo de letrados realizó una visita al nosocomio para constatar la situación del artista, la cual había "querido exagerarse en sentido desfavorable"17. En ese marco, a petición de la señora Soledad Cortés de García, madre del novelista, se efectuó una nueva valoración médica del enfermo a cargo de un desconocido médico de nombre Celso Nava, quien certificó que Castera estaba en "estado satisfactorio de la enajenación mental que adolece" ${ }^{18}$, por lo que solicitó a las autoridades correspondientes su pronta recuperación en una casa que la familia tenía en Tacubaya. Ante la presión de la madre y de los colegas que habían confirmado los deseos del paciente de abandonar San Hipólito, Govantes volvió sobre el caso y consideró peligrosa su salida. La negativa desató todo tipo de argumentaciones conspiracionistas sobre la supuesta retención forzada del poeta; frente a las críticas, aunque el director estaba convencido de que los delirios eran una manifestación elocuente de su peligrosidad, aseguró: "creo que si se sigue atendiendo convenientemente, tal vez vuelva al pleno goce de sus facultades intelectuales; mas juzgo que por el momento se halla en un estado delicado, y que sería peligroso que saliera ahora del hospital de una manera definitiva"19.
A pesar de lo anterior, el cuestionamiento público sobre la permanencia injustificada y las solicitudes de apoyo para que Castera saliera de San Hipólito obligaron a que funcionarios y médicos tomaran una postura firme al respecto. Con el objetivo de avalar su diagnóstico y de remarcar la peligrosidad del confinado, a finales de mayo se difundió en la prensa capitalina otro certificado realizado por médicos de reconocido prestigio: Rafael Lucio, Alberto Cervantes y el mismo Govantes, en el cual se detalló que el poeta sufría de "lipemanía y delirio de persecución"20. Ambos conceptos, como es sabido, fueron esenciales para el desarrollo del alienismo francés de la primera mitad del siglo XIX. El primero se entendía como una enfermedad del cerebro, cuyos síntomas eran delirios y una tristeza debilitante y abrumadora (Berrios, 2008, p. 382); en el segundo, el loco presentaba alucinaciones auditivas y visuales como respuesta a los efectos del exterior (Bercherie, 2014, pp. 62-63). Cabe advertir que los dos diagnósticos reseñados se realizaron nueve o diez meses después del internamiento del autor, razón por la cual no es posible determinar si los síntomas aparecieron antes o como resultado de éste ${ }^{21}$.

La inestabilidad en la identificación nosológica del padecimiento de Castera no sólo permite vislumbrar el estado y los problemas que enfrentó la incipiente medicina mental en México, sino que también, en otro nivel, abre la posibilidad de proponer una nueva hipótesis acerca del origen de su confinamiento. Antes de ello, convendría señalar que para ingresar a un individuo en San Hipólito, por reglamento, era necesario presentar un certificado firmado por dos médicos que avalaran la enfermedad; sin embargo, ante la falta de una normativa federal para impedir los "ingresos involuntarios" y el estado en que se encontraban en ese momento las instituciones manicomiales en México, era usual que las familias tomaran el control del internamiento de sus $\operatorname{locos}^{22}$. El episodio que nos ocupa bien puede ejemplificar tal situación, pues, posiblemente, la reclusión se dio en contra de su voluntad y motivada por una herencia de bienes familiares, como expondremos a continuación.

Cuando Pedro Castera anunció su salida del diario La República para atender "negocios importantes" estaba iniciando una pugna legal por unas tierras heredadas en Michoacán. Existen indicios de que, una vez confinado en San Hipólito e incapacitado legalmente, el poeta enfrentó una demanda interpuesta por Antonio Ramos Cadena en el juzgado 4to de lo 
civil $^{23}$. Tal elemento resulta clave para plantear esa ruta interpretativa sobre su proceso de reclusión. En el Código Civil de 1870, que entró en vigor un año después, se incluía la figura legal del juicio de interdicción, mecanismo mediante el cual se incapacitaba jurídicamente a menores de edad y a personas "privadas de inteligencia por locura, idiotismo e imbecilidad"24. Así, ser diagnosticado loco convertía al individuo en sujeto de custodia, por lo que la persona no podía hacer uso de sus bienes, los cuales debía administrar un tutor legal. En otras palabras, dichos juicios sólo tenían sentido cuando había propiedades materiales de por medio, y podían ser solicitados por el cónyuge, los herederos legítimos o el ejecutor testamentario. El caso Raygosa (1873-1877) fue, probablemente, el primer juicio de interdicción en llevarse a cabo luego de la promulgación del Código. Manuela, esposa del abogado Felipe Raygosa, levantó la demanda al considerar que su marido estaba despilfarrando el dinero de la familia; el inculpado, por su parte, intentó defenderse en los juzgados de las opiniones de los facultativos, que lo veían como un monomaniaco ambicioso (Sacristán, 1999).

El episodio anterior presenta algunas coincidencias con el de Castera. Luego del internamiento de éste, se designó al licenciado Bermejo como su tutor legal; empero, meses después, lo sustituyó el reconocido abogado, periodista y diputado Juan Vicente Villada, quien, en una carta publicada el 3 de junio de 1884, recalcó que fue la familia del novelista la que solicitó el juicio de interdicción ${ }^{25}$. Además, destacó el profundo aborrecimiento que su apoderado tenía hacia "la respetable autora de sus días". Asimismo, ante las acusaciones de que Castera no recibía sus dietas como diputado, Villada aseguró desconocer otros intereses, pues, al requerir a la familia los documentos oficiales del escritor, reconoció de forma pública que nunca pudieron entregárselos debido a que una tía, "también demente", los resguardaba celosamente. Lo expuesto permite suponer que Castera pudo haber sido internado por sus parientes, quienes aprovecharon los aludidos vacíos legales que imperaban en San Hipólito, y, una vez confinado, los médicos se encargaron de certificar su locura.

Hacia finales de noviembre de 1884 , de modo un tanto sorpresivo, la madre de Castera envió una misiva al director de El Monitor Republicano para que, a través de su medio, lograra persuadir a las autoridades de sacar a su hijo del nosocomio ${ }^{26}$. Tal solicitud, al parecer, fue atendida por las instancias médicas, pues, por esas fechas, Castera dejó San Hipólito sin testimonio alguno que lo registrara ni sentencia que diera indicios de la situación legal del escritor. Por desgracia, no pudimos localizar ningún documento que atestiguara el proceso ni las condiciones de salida del poeta del sanatorio, por lo cual deducimos que bien pudo deberse a la presión mediática ejercida tanto por su progenitora como por diversos miembros de los campos político y literario, con quienes estuvo relacionado el autor y que, al menos estos últimos, dieron una lectura particular a tan infortunada incursión.

\section{"Pues que la suerte con saña fiera te hundió EN EL CAOS DE LA DEMENCIA"}

A pesar de que la revisión de las fuentes parecería privilegiar la hipótesis de que el internamiento de Castera se debió a un juicio de interdicción, ésta no resuelve otras incógnitas relacionadas con las múltiples representaciones que sujetos de diferentes disciplinas hicieron de su mal, las cuales mediaron no sólo la recepción de su obra, sino, incluso, la re-configuración de su imagen como escritor. Al respecto, cabría insistir en la extensa cobertura periodística que se dio a la demencia casteriana; diarios de varias latitudes de la República de tendencias ideológicas y políticas diversas escribieron o reprodujeron, como señalamos, noticias, entrevistas, informes médicos o comentarios relativos a la salud y situación del escritor en San Hipólito. Aunque en esas distintas textualidades se construyó de modo bifronte la figura de Castera, en todas ellas, la presencia de la enfermedad mental permitió visibilizar la posición que el autor ocupaba en la esfera pública y en el campo literario, en una etapa de transición en la que las prácticas discursivas no sólo oficialistas, sino también artísticas evidenciaban el ineludible influjo de la narrativa positivista que se apoyó tanto en el referente cientificista (Nouzeilles, 2000; Zavala, 2012), como en la literatura médica de la época, acorde con el impulso modernizador porfiriano (Hale, 2002).

Desde tal perspectiva, en la prensa periódica la insania de Castera se abordó, en principio, a partir de sus implicaciones médico-legales, relacionadas con el trabajo del escritor como funcionario. Ello explica, nos parece, la ubicación un tanto periférica de la información dedicada a su caso, incluida, por lo general, en la gacetilla o en los espacios destinados a la crónica parlamentaria. En esos textos, el poeta es descrito 
como un individuo incapaz de seguir cumpliendo sus labores políticas. Su deteriorado estado mental lo inhabilitaba para realizar dichas funciones, transfigurándolo en un sujeto marginal a las instancias de poder, a la cuales antes pertenecía y que serían las encargadas de dirimir sus conflictos legales y monetarios ${ }^{27}$.

Por su carácter "oficial", esos documentos se enuncian desde una supuesta "objetividad", cuyo principal recurso narrativo es la descripción concisa tanto del espacio hospitalario como del estado físico del "paciente". En la sesión de la Cámara de Diputados del 11 de octubre de 1883, por ejemplo, el mencionado diputado Villada, quien, según advertimos, después fungió como tutor legal del escritor, expuso frente al Congreso las condiciones en las que se hallaba: "en cuanto a los alimentos y otras necesidades [...] carecía aun de lo más preciso, teniendo su ropa desgarrada y siendo la misma con que había ingresado [a San Hipólito] hacía tres meses"28. Como se observa, la centralidad de la enfermedad anuló, por completo, cualquier referencia al pasado desempeño de Castera como funcionario, es decir, al prestigio alcanzado por ocupar una curul; por el contrario, su figura se proyectó sólo como la de un desheredado, acorde con las ideas que se tenían acerca de los pacientes mentales.

Para validarse, el discurso legal descansó en la opinión clínica, encargada de certificar el malestar casteriano en consonancia con los paradigmas de la ecléctica práctica médica mental en el país, cuyos principios nosológicos se estaban discutiendo. En esa línea, cabría recordar que apenas un año antes, en 1881, se dio a conocer el dictamen de la Comisión de Manicomios, en el que no sólo se argumentó la necesidad apremiante de construir un moderno hospital general para dementes, sino que también se planteó la urgencia de actualizar los presupuestos de la clínica mental mexicana, tomando como modelo "los escritos de los alienistas europeos más destacados [...] por sus teorías sobre la locura [... y] por sus aportaciones en la construcción y organización de asilos", entre los que despuntaron los nombres de expertos franceses, tales como Morel, Esquirol y Pinel (Mancilla, 2001, pp. 129-130).

No obstante lo expuesto, el peso de este discurso clínico fue contundente en la configuración del retrato del poeta como un ser alienado y peligroso para la seguridad del organismo social, razón por la cual debía estar bajo la custodia especializada del saber médico estatal. Al respecto, resultan significativas, por una parte, las palabras de Govantes, cuando, como se apuntó, la familia del escritor y algunos periodistas intentaron cuestionar la decisión de alargar su estadía en el manicomio: "no basta", afirmó, "un buen criterio para resolver cuestiones que requieren conocimientos especiales" ${ }^{29} ;$ y, por la otra, la relatoría en términos casi cronísticos del fallido experimento, que consistió en reinsertar a Castera de forma momentánea en la realidad cotidiana, mediante el aludido paseo por la Alameda de la Ciudad de México. De acuerdo con el facultativo, "a la vista de edificios que le traían recuerdos, y por el encuentro de algunos amigos que le impresionaron vivamente", el poeta comenzó a tener alucinaciones auditivas "y se fue excitando al grado de que [tuvieron que apresurarse] a regresar al manicomio"30.

Si bien el pretendido carácter científico de esos textos resulta cuestionable ante la enunciación de diferentes diagnósticos a lo largo de la estancia del escritor en aquel establecimiento, dicha oscilación nos parece reveladora en la medida que, por un lado, reforzó la naturaleza dual de la personalidad de Castera, escindido entre el campo político y literario y, por el otro, en diferente nivel, entró en diálogo con una serie de ideas relacionadas con las supuestas tendencias patológicas del agente creador. Al igual que en diversas latitudes de Occidente, en México la disputa por alcanzar una mayor legitimidad y poder cultural implicó que miembros del gremio médico miraran con recelo a diferentes sectores poblacionales y profesionales; en particular, el de los artistas les resultó altamente inquietante, porque, de acuerdo con el discurso positivista de la época, sus "rasgos diferenciadores" de personalidad, sobre todo su extrema sensibilidad y su supuesta predisposición a la locura, los convertían en seres "que no podía[n] considerarse dentro de [la] 'normalidad' que la sociedad burguesa pretendía imponer a toda costa" (Huertas, 1987, pp. 143-144).

Una muestra modélica de esta visión que se proyectó de los artistas, en general, y de los escritores, en específico, se encuentra en los textos del reconocido doctor Luis E. Ruiz, quien impartía la cátedra de Higiene en la Escuela de Medicina en la década de los ochenta. En su Tratado elemental de higiene, el galeno propuso una clasificación de los diferentes sectores que conformaban a la sociedad mexicana; en el último grupo incluyó a los "hombres de letras", integrado por abogados, médicos, ingenieros, educadores y literatos. A pesar de que la "predominancia 
del trabajo intelectual sobre la actividad manual" predisponía a los "hombres de letras" a desarrollar las mismas enfermedades (Ruiz, 1904, pp. 345-346), Ruiz trazó una clara línea divisoria entre esos profesionistas y los creadores; para ello, utilizó como herramienta axial de validación las estadísticas, según las cuales la incidencia de locura era mayor en esta última agrupación debido a su evidente falta de templanza y de contención emocional, pero también al uso excesivo de la imaginación, inclinaciones que dotaron a estos sujetos de una especie de "naturaleza" ambigua (femenina-masculina), que podía resultar peligrosa para el sano desarrollo de los potenciales lectores nacionales.

Tomando en cuenta lo anterior, no nos parece fortuito que la clasificación terminológica de la enfermedad de Castera se desplazara de una inicial "monomanía del níquel" hacia una "lipemanía", cuyo síntoma principal, según se dijo, era una tristeza debilitante y abrumadora. A inicios del siglo xIX, Pinel y Esquirol se esforzaron por proponer cambios conceptuales y desterrar de la medicina mental cualquier reminiscencia de las "ideas hipocráticas-galénicas" sobre los humores (Starobinski, 2016, p. 23). Una de las acciones que emprendieron fue la acuñación del término "lipemanía" en renuevo de la voz "melancolía", la cual remitía a un malestar y a un temperamento asociados desde la Antigüedad con cierta superioridad intelectual y genialidad artística, creencia que tuvo una larga pervivencia en el imaginario colectivo y que resultó en suma productiva para diversas corrientes, tanto filosóficas como estéticas, en Occidente.

En esa lógica discursiva, la redacción del dictamen médico firmado por destacados galenos presentó, sin duda, un claro sesgo estético, mediado con seguridad por el prestigio que Castera había alcanzado en el terreno de las letras previo a su internamiento, así como por las otras narrativas generadas a propósito de su ingreso a San Hipólito, con las cuales dialogaron las de índole médico-legal, dado que ambas aparecieron de manera simultánea en las páginas de los mismos periódicos. A diferencia de la concisión y "asepsia" que caracterizó los documentos clínicosjurídicos, en esos otros textos de carácter más ficcional que informativo se configuró la imagen de un Castera sufriente, infortunado miembro de un campo literario que, por aquellas fechas, experimentaba también los efectos del incipiente proceso de modernización en el país. Las transformaciones del sistema económico, a la vez que la tendencia hacia la división del trabajo que propició el fenómeno de la especialización, incidieron en el ejercicio escritural. Para integrarse al mundo capitalista, los autores se enfrentaron a la exigencia de desarrollar estrategias laborales para satisfacer sus anhelos creativos y sus necesidades monetarias. El periodismo fue una de las actividades que les permitió cumplir ambas cuestiones; sin embargo, también se convirtió en un quehacer absorbente que, de acuerdo con algunos, los enfermaba y minaba sus capacidades artísticas, pues los sometía a la presión de la entrega diaria o semanal y a los requerimientos de editores y de un público cada vez más ávido de noticias (Moretic, 1975, pp. 59-60; Rotker, 1991; Clark de Lara, 1998) ${ }^{31}$.

Ciertamente, el caso de Castera se leyó desde esta perspectiva en las colaboraciones antes mencionadas; así, sirvió como una vía para denunciar y exponer las difíciles condiciones que enfrentaban los literatos para ejercer su profesión, pues sufrían las consecuencias del excesivo trabajo intelectual, origen de diversos padecimientos psicosomáticos. La demencia de Castera se presentó ante los lectores como un síntoma y malestar producto de la modernidad, cuyas exigencias herían a creadores sensibles como el autor de Carmen, quien había "sucumbido al trabajo, como todos los grandes artistas" 32 . Uno de sus primeros visitantes en San Hipólito, el referido Marqués d’Equevilley, recreó la figura del novelista cual la de un héroe romántico caído por el peso del infortunio moderno. "Allí estaba", apuntó, "detrás de la reja confundido en medio de sus desgraciados compañeros y en el triste estado [...]. Su poderosa naturaleza [estaba] aniquilada por el sufrimiento moral, su cara amarilla, su barba inculta y ya cana, sus manos temblorosas... iah! ¿Por qué esta frente pensadora ha sido herida por el rayo implacable de la fatalidad?"33

Contraria a la palabra médico-legal, esta narrativa doliente fundó su legitimidad en lo emotivo, en la pertenencia de los escritores a una comunidad afectiva, cuya hipersensibilidad los distinguía del ciudadano común, a quien, finalmente, también se buscó conmover, quizá con propósitos más económicos que culturales. De ese modo, la melancolía del paciente encontró un correlato en el discurso sufriente de quien se sabía, de igual forma, preso de la condición dual de escritor-periodista, sometido a las presiones del orden capitalista. De tal suerte, en el citado texto del Marqués d'Equevilley abundaron frases como: "las lágrimas me vienen a los ojos" o "Padecía demasiado para prolon- 
gar más mi dolorosa entrevista", que, a su vez, se reprodujeron en términos semejantes en otras notas relativas a la infortunada situación de Castera. Por ejemplo, el mencionado poeta Agustín F. Cuenca describió el espacio nosocomial en consonancia con ciertos tópicos románticos; el manicomio se presentó a los ojos de los lectores cual tétrica ruina, donde permanecería atrapado el espíritu artístico: última morada del creador caído ante una realidad que lo oprimía y lo enloquecía. "Al pasar frente a ese triste edificio", se condolió Cuenca, "sentimos violentamente oprimido nuestro corazón, [...] allí, detrás de aquellos altos y sombríos muros, estaba nuestro amigo, el poeta entusiasta, el soñador impetuoso, el hombre caballero, más altivo en el infortunio que en la prosperidad"34. Una especie de consagración artística convirtió a Castera en sujeto de creación literaria, no sólo en estos textos en prosa de carácter híbrido, sino también en composiciones en verso, en las que el yo lírico estableció una relación de complicidad y empatía con el "genio" abatido, en la medida que compartía su desventura como miembro del ámbito literario. En el poema "A Pedro Castera", A. Peredo Hoyos se compadeció de la pérdida de la razón del escritor, en términos muy cercanos a los empleados en la prosa cronística:

Campeón sublime
fuiste en la prensa,
grande filósofo,
alma de atleta,
alma que mundos
de luz encierra,
sensible siempre,
siempre serena,
porque grandioso
tu genio era,
de aquellos genios
que regeneran
con la fe augusta
de la conciencia ${ }^{35}$.

Al igual que en la narrativa clínica, en estas composiciones subyacería la antigua creencia aristotélica de la existencia de un vínculo entre melancolía, genialidad y locura, que se resignificó a partir de los principios de la medicina mental a lo largo del siglo $\mathrm{XIX}$, con especial insistencia tras el surgimiento del movimiento romántico. Sin embargo, en dichas colaboraciones periodísticas, la tendencia patológica del agente creador no tendría una lectura negativa; por el contrario, la hipersensibilidad del autor de Carmen, y su demencia melancólica serían leídas como la marca de Caín que garantizaba su pertenencia al mundo del arte. En un sentido más profundo, para estos autores, la disposición anímica de Castera -y de los artistas en general- no encarnaba una amenaza para la sanidad ni el buen funcionamiento de la sociedad porfiriana, sino una forma de resistencia intelectual creativa contra la deshumanización y el materialismo que acechaba a las nuevas generaciones. La manifiesta tensión entre las posturas médicas y literarias sobre la locura bien puede interpretarse, según dijimos, como la búsqueda de reconocimiento y prestigio que los agentes de ambos campos buscaron alcanzar en un momento de patentes transformaciones socioeconómicas y culturales.

Desde esta perspectiva, la construcción de la figura de Castera como la de un genio-loco contribuyó a darle mayor notoriedad pública y a incrementar su capital simbólico y económico en los años posteriores a su salida de San Hipólito. Una serie de datos dispersos en las publicaciones periódicas confirman esa transición, mucho más clara a partir de enero de 1887, cuando se informó en la prensa que "deseando impedir que sus [obras fueran reimpresas] con perjuicio de sus derechos, [el autor conservaba] la propiedad literaria que le [correspondía]"36. Dicha noticia apunta hacia el hecho de que el aludido proceso legal no lo incapacitó para el usufructo de sus producciones, lo cual tiene sentido en aquel medio incipientemente capitalista que veía con desprecio y recelo la labor creativa, en apariencia improductiva, de los artistas.

Aunado a lo anterior, en los meses posteriores a ese anuncio, se informó que, una vez agotada la primera edición en forma de libro de la novela Carmen, el taller de Eufenio Abadiano se disponía a preparar la segunda edición ${ }^{37}$, dentro de la colección Biblioteca Histórico-Literaria, más tarde sólo Biblioteca Mexica$\mathrm{na}^{38}$. El volumen prometido contó con un prólogo del reconocido militar y novelista liberal Vicente Riva Palacio (1832-1896), quien hizo de la novela de Castera un emotivo manifiesto literario en contra del materialismo positivista y del determinismo biológico darwiniano, cuya hegemonía se discutía por aquellas fechas en la prensa (Moreno, 1989). De acuerdo con Ana Chouciño Fernández y Leticia Algaba (2003), en esas páginas Riva Palacio defendió la función emotiva, didáctica y moral de la literatura, enfrentada al escepticismo de la ciencia. La obra de Castera se consagró, así, como un alegato en favor de la autonomización del campo literario al oponerse a la presión de instancias de reconocimiento externas a éste, a la vez que como un discurso amoroso, mediante el cual 
se pretendía fortalecer los vínculos "emocionales", pero también de consumo, con los lectores.

Pocos meses después de la aparición de la nota sobre la nueva edición de Carmen, en noviembre de 1887, comenzó a publicarse, otra vez por entregas, el volumen de Las minas y los mineros en la casa editora de "Filomeno Mata, esquina de Betlemitas y San Andrés" 39 . En la sesión del 11 de noviembre de aquel año, el autor dirigió una petición a la Cámara de Diputados para que este organismo comprara doscientos ejemplares de la obra ${ }^{40}$, la cual fue, además, traducida al alemán por el editor Isidoro Epstein en $1889^{41}$. Finalmente, a mediados de 1890 , en las páginas de El Siglo Diez y Nueve, Rafael de Zayas Enríquez, con el seudónimo de Anacreonte, comentó ufano en una de sus "Crónicas de la semana" que "la afamada casa editorial de Garnier, de París, [iba] a fundar una sucursal en México", cuyo "noble propósito" sería "explotar la literatura mexicana, comprando obras inéditas a nuestros más renombrados escritores", para lo que ya había establecido contratos con autores como Castera y Gutiérrez Nájera ${ }^{42}$.

\section{CONSIDERACIONES FINALES}

Aun cuando resulta en suma complejo rastrear las huellas de los lectores de una época, sus prácticas, preferencias y hábitos de consumo literarios, consideramos que los datos hasta aquí presentados demuestran que el episodio nosocomial de Pedro Castera medió la recepción de su obra después de 1883. La información expuesta nos inclina a pensar que un segmento del público porfiriano se acercó con deleite morboso a la casi novelesca narración de los infortunios del melancólico poeta, cuyas obras serían, a partir de entonces, leídas bajo la sombra de la locura por algunos sectores letrados. Más aún, proponemos que el caso generó tanta atención mediática porque evidenció de manera intensiva no sólo la postura de los escritores-periodistas ante las circunstancias de su entorno, sino también las difíciles condiciones que enfrentaban para ejercer la escritura y para que ésta fuera reconocida como una actividad profesional productiva y, sobre todo, útil para la sociedad.

El propio escritor fue consciente de esto, como puede constatarse en el significativo inicio de una de sus últimas obras literarias, Dramas en un corazón, en la que reflexionó sobre las emociones descontroladas y la perturbación mental en relación directa con la función "moral" que le atribuyó a literatura. En una vuelta de tuerca, en esas palabras liminares, el narrador se invistió de una especie de autoridad clínica para abordar estéticamente la disección de los "profundos abismos" del corazón humano, cuyos problemas podían diagnosticarse como "enfermedades de la mente o como deformidades morales", producto de "la influencia nerviosa y de la debilidad cerebral" (Castera, 1987, p. 285). La experiencia manicomial, entonces, dotó al escritor tanto de los conocimientos "médicos" como de la legitimidad cultural necesarios para validar el tratamiento literario de dichos malestares, con el objetivo de "depurar la conciencia y [...] dilatar nuestras facultades [,] ennobleciéndolas" (Castera, 1987, p. 286). El creador lograría tan alto cometido por medio de la generación de impresiones contrastivas, que conmoverían al lector y disciplinarían sus emociones mediante el miedo a la locura y al crimen; en palabras del narrador:

Las antítesis, en la vida moral, son semejantes a los estudios de sombras en la pintura o en el grabado; de aquí la contemplación de esos cuadros que, como las aguas fuertes, son más bien el estudio de las líneas y de los tonos, con una sola base: el color negro, o lo que es igual, la ausencia de todos los colores; del fondo sombrío viene a desprenderse la luz y a convertirse entonces en otro nuevo género de estudio: el estudio del claroscuro (Castera, 1987, p. 286).

Aunque, como hemos analizado a lo largo de este trabajo, el ingreso del escritor Pedro Castera al manicomio se produjo en el contexto de un litigio legal, las diferentes lecturas que se dieron al hecho tuvieron consecuencias muy diversas para el autor; de esta suerte, mientras que en el ámbito político su supuesta pérdida de la razón lo inhabilitó para seguir cumpliendo con sus actividades públicas y legislativas, a las cuales nunca más se reincorporó, en el ámbito literario su locura fue leída a la luz de las ideas referentes a la genialidad y al arte que imperaban en la época, pero también, importa decirlo, de las tensiones entre las narrativas de diversos campos en pugna por la hegemonía cultural, producto de los reacomodos sociales que provocó el complejo fenómeno de la modernidad en un país que hacía intentos desesperados por ingresar al orden mundial. Desde tal perspectiva, la locura melancólica de Castera fue una importante advertencia para los lectores sobre la delgada línea que separaba la salud de la enfermedad mental, en el contexto desarrollista del México finisecular. 


\section{NOTAS}

1 Agustín Galindo perteneció al Colegio del Estado de Puebla y a la Sociedad Médico Farmacéutica del mismo estado. Realizó investigaciones sobre meteorología, la influencia de la atmósfera en la salud y el tratamiento de la sífilis (Estrada, 1993).

2 La nota se publicó originalmente en una gacetilla del diario La Luz del estado de Puebla, del cual la retomaron otros diarios capitalinos: "Pedro Castera", El Siglo Diez y Nueve, 21.06.1883, p. 3; “D. Pedro Castera”, La Voz de México, 26.06.1883, p. 1

3 Por ejemplo, Federico Mendoza y Vizcaíno señaló que la novela "ha deleitado a cuantos la han leído y, ha hecho sentir las emociones más delicadas a cuantos la han sabido comprender". Federico Mendoza y Vizcaíno, "Carmen", La Patria, 28.04.1882, p. 2. Para un estudio histórico-filológico, Chouciño y Algaba, 2003; Sandoval, 2005.

4 Incluso los redactores del diario convocaron a todos aquellos interesados en comprar la novela a acudir a la calle de San Andrés número 9 1/2, en la Tipografía Literaria del diario capitalino. "Carmen", El Diario del Hogar, 25.02.1882, p. 4; "Carmen", El Diario del Hogar, 25.03.1882, p. 4; "Carmen", El Siglo Diez y Nueve, 08.04.1882, p. 3.

5 “Un manicomio", El Monitor Republicano, 05.05.1882, p.

6 Con la victoria del Plan de Tuxtepec en 1876, comenzó una de las etapas más extensas en la vida independiente de México: el Porfiriato (1876-1911). Por la larga duración de este periodo, su análisis se ha divido en tres momentos: de 1876-1891, que corresponde a la instalación y al afianzamiento del régimen de "Paz, orden y progreso", encabezado por los generales Porfirio Díaz y Manuel González; de 1892-1900, que marca la transformación de Díaz en el hombre necesario e irremplazable, que posibilitó una evidente estabilidad tanto política como monetaria; y de 1901-1911, que concierne al ocaso del dictador, quien, al negarse a dejar el poder, provocó una ruptura entre los grupos que lo habían apoyado, lo cual dio paso al estallido de la Revolución en 1910.

7 La República. Semanario Literario, 01.01.1882, p. 1.

8 "A los señores corresponsales y suscriptores de La República", La República. Periódico Político y Literario, 28.07.1882, p. 1

9 Archivo Histórico de la Secretaría de Salud. Fondo: Beneficencia Pública, Sección: Establecimientos Hospitalarios, Serie: Hospital de San Hipólito, legajo 4, expediente: 1, 1883, f. 17. (AHSS)

10 "An afflicted author", The Two Republics, 02.11.1883, p. 1.

11 La versión de que Castera fue enviado a San Hipólito por negarse a realizar una campaña en favor del níquel surgió de una comunicación personal entre el escritor Luis González Obregón y el crítico Carlos González Peña (1950, p. 16).

12 Ante la inconformidad de amplios sectores de trabajadores por la puesta en circulación de la moneda de níquel, que afectaba principalmente la economía de los comerciantes, en la Ciudad de México se organizaron diversos movimientos de protesta popular reunidos en los mercados de la Merced y del Volador, que rechazaban la moneda y buscaban poner fin a la devaluación, al alza de los precios y a la recaudación de nuevos impuestos.

13 Marqués d'Equevilley, "Visita a Pedro Castera", El Monitor Republicano, 01.11.1883, p. 3.

14 "La recepción de la monomanía en los tribunales mexicanos durante la segunda mitad del siglo XIX", texto presentado en el III Coloquio del Seminario Interdisciplinario en Salud Mental. La circulación, recepción y reinterpretación de saberes "psi", siglos XIX-XX, en el 2016. Agradecemos a la Dra. Sacristán habernos proporcionado el impreso.

15 En esa lógica discursiva, el periódico gubernamental El Diario Oficial ratificó la versión de que el poeta era "víctima de una perturbación mental" y, por consiguiente, debía permanecer en el nosocomio con la garantía de que estaba recibiendo las mensualidades correspondientes en su calidad de servidor público. El Diario Oficial, 03.11.1883, p. 3.

16 En dicho artículo, el autor manifestó: "Conducido al hospital de locos de San Hipólito desde hace algunos meses, y creyendo incurable su mal por los informes que se nos dieron, habíamos renunciado para siempre a la esperanza de verle y estrecharle entre nuestros brazos: no hemos tenido ni habríamos llegado a tener valor para buscar al querido amigo, víctima de la más negra de las fatalidades". Agustín F. Cuenca, "Pedro Castera”, La Prensa, 03.01.1884, p. 3.

17 "Una visita a Pedro Castera", El Diario del Hogar, 28.05.1884, p. 4.

18 “El clamor público", El Nacional, 29.05.1884, p. 3.

19 Juan Govantes, "Informe", El Monitor Republicano, 05.06.1884, p.3.

20 "El Sr. Pedro Castera", El Monitor Republicano, 03.06.1884, p. 3.

21 En el AHSS, no existe el expediente clínico de Pedro Castera, ni el de un buen número de internos del Hospital de San Hipólito. Aunque estaba estipulado en el reglamento interno que los facultativos debían realizar una valoración médica, muchas veces no la consignaban.

22 La normativa que permitió frenar los internamientos involuntarios apareció hasta 1995 (Sacristán, 1998, p. 209).

23 "Juzgado 4to de lo civil", El Tiempo, 23.10.1883, p. 4; “Juzgado 4to de lo civil", El Tiempo, 01.11.1883, p. 4.

24 Código Civil del Distrito Federal y Territorios de Baja California, México, Imprenta de E. Ancona y M. Peniche, 1871, pp. 241-245.

25 Juan Vicente, Villada, "El Sr. Pedro Castera", El Monitor Republicano, 03.06.1884, p. 3.

26 Soledad Cortés, "Al señor editor de El Monitor Republicano", El Monitor Republicano, 28.11.1884, p. 4.

27 No es casual, en ese sentido, que, tal como documenta Dulce Adame, el "asunto [llegara] a instancias de la Secre- 
taría de Gobernación”, y que el propio Carlos Díez Gutiérrez fuera quien negara "el permiso para que Castera saliera del Hospital" (2015, p. 43).

28 "Cámara de Diputados", El Monitor Republicano, 13.10 .1883 , p. 4

29 Juan Govantes, "Informe", El Monitor Republicano, 05.06.1884, p. 3.

30 Juan Govantes, "Informe", El Monitor Republicano, 05.06.1884, p. 3.

31 Al respecto, cabría señalar que la generación de escritores anterior a la de Castera, la del nacionalismo cultural, participó activamente en el diseño, real y simbólico, de las instituciones que sentaron las bases del Estado liberal mexicano después de la caída de Imperio de Maximiliano en 1867. Durante ese periodo, el ejercicio de las letras les permitió a muchos autores, además de escribir en diversos medios impresos y gozar del usufructo de sus obras, colaborar de manera directa con las altas esferas políticas y sociales, desempeñando distintas funciones -ya fuera como militares, ministros de Justicia, secretarios de Estado o diputados en el Congreso de la Unión-, por las cuales también recibieron una remuneración económica. Con las transformaciones emanadas del fenómeno modernizador, los creadores fueron desplazados hacia otros campos, como los del periodismo y la docencia, para conseguir su sustento (Gutiérrez, 1987, pp. 496-499). De acuerdo con Ángel Rama, aquel proceso terminó diversificando las actividades profesionales de los escritores, quienes "encontraron que podían ser 'reporters' o vender artículos a los diarios, vender piezas a las compañías teatrales, desempe- ñarse como maestros pueblerinos o suburbanos, escribir letras para las músicas populares, abastecer los folletines o simplemente traducirlos, producción suficientemente considerable como para que al finalizar el siglo se establecieran las leyes de derecho de autor y se fundaran las primeras organizaciones destinadas a recaudar los derechos intelectuales de sus afiliados" (Rama, 1984: 74-75).

32 P. A. Sauvalle, “M. Pedro Castera”, Le Trait d'Union, 01.11 .1883 , p. 3

33 Marqués d'Equevilley, "Visita al poeta Pedro Castera", El Monitor Republicano, 01.11.1883, p. 3.

34 Agustín F. Cuenca, "Pedro Castera”, La Prensa, 03.02.1884; reproducido en Luis Mario Schneider (1987), "Introducción" a Pedro Castera.

35 A. Peredo Hoyos, "A Pedro Castera", El Monitor Republicano, 18.11.1883, p. 2

36 “Propiedad literaria”, El Tiempo, 30.01.1887, p. 4.

37 “Carmen”, El Diario del Hogar, 21.08.1887, p. 3.

38 “Gracias", El Tiempo, 23.10.1887, p. 4.

39 "Avisos", Diario del Hogar, 29.11.1887, p. 4

40 “Crónica parlamentaria”, El Siglo Diez y Nueve, 12.11.1887, p. 3.

41 "Las minas y los mineros", El Municipio Libre, 06.04.1889, p. 3.

42 Anacreonte [Rafael de Zayas Enríquez], "Correo de la semana", El Siglo Diez y Nueve, 05.07.1890, p. 1.

\section{BIBLIOGRAFÍA}

Adame González, Dulce María (2015), “Estudio preliminar”. En: Castera, Pedro, Ensueños y armonías y otros poemas, México, Universidad Nacional Autónoma de México, pp. 25-164.

Bercherie, Paul (2014), Los fundamentos de la clínica. Historia y estructura del saber psiquiátrico, Buenos Aires, Manantial.

Berrios, Germán E. (2008), Historia de los síntomas de los trastornos mentales. La psicopatología descriptiva desde el siglo $x I X$, México, Fondo de Cultura Económica.

Campos, Ricardo; Martínez Pérez, José; Huertas, Rafael (2000), Los ilegales de la naturaleza. Medicina y degeneracionismo en la España de la Restauración (1876-1923), Madrid, Consejo Superior de Investigaciones Científicas.

Campos, Rubén M. (2013), El Bar. La vida literaria en México en 1900, México, Universidad Nacional Autónoma de México.

Castera, Pedro (1987), Impresiones y recuerdos. Las minas y los mineros. Los maduros. Dramas en un corazón. Querens, México, Patria.
Chouciño Fernández, Ana; Algaba, Leticia (2003), "Lectores y lecturas de Carmen de Pedro Castera", Literatura Mexicana, 14 (1), pp. 87-111.

Clark de Lara, Belem (1998), Tradición y modernidad en Manuel Gutiérrez Nájera, México, Universidad Nacional Autónoma de México/Instituto de Investigaciones Filológicas.

Estrada Urroz, Rosalinda (1993), “Entre Ricord y Fournier: la polémica de médicos sobre la utilización del mercurio en el tratamiento de la sífilis". En: Pérez-Siller, Javier; Cramaussel, Chantai (coords.), México-Francia. Memoria de una sensibilidad común, siglos $X I X-X X, I I$, México, Centro de Estudios Mexicanos y Centroamericanos, pp. 291-315 [en línea] disponible en: http://books.openedition.org/cemca/855 [consultado el 12/10/2017].

Foucault, Michel (1976), Yo Pierre Riviere habiendo degollado a mi madre, hermana y hermano. Un caso de parricidio del siglo XIX, Barcelona, Tusquets.

Gantús, Fausta; Salmerón, Alicia (2014), “Introducción”. En: Gantús Fausta; Salmerón, Alicia (coords.), Prensa y elecciones. Formas de hacer política en el México del siglo XIX, México, Instituto Mora, pp. 11-25. 
González Peña, Carlos (1950), "Prólogo". En: Castera, Pedro, Carmen. Memorias de un corazón, México, Porrúa, pp. 7-17.

Gutiérrez, Florencia (2013), “El motín del níquel. Móviles materiales. Percepciones políticas e hispanofobia. Ciudad de México, diciembre de 1883". En: Salmerón, Alicia; Aguayo, Fernando (coords.), Instantáneas de la Ciudad de México. Un álbum de 1883-1884, I, México, Instituto Mora, pp. 137-150.

Gutiérrez Girardot, Rafael (1987), "La literatura hispanoamericana de fin de siglo". En: Íñigo, Luis (coord.), Historia de la literatura hispanoamericana, II. Del neoclasicismo al modernismo, Madrid, Cátedra, pp. 495-506.

Hale, Charles A. (2002), La transformación del liberalismo en México a fines del siglo XIX, México, Fondo de Cultura Económica.

Huertas, Rafael (1987), Locura y degeneración. Psiquiatría y sociedad en el positivismo francés, Madrid, Consejo Superior de Investigaciones Científicas/Centro de Estudios Históricos.

Huertas, Rafael (2012), Historia cultural de la psiquiatría, Madrid, Libros de la Catarata.

Mancilla Villa, Martha Lilia (2001), Locura y mujer durante el Porfiriato, México, Círculo Psicoanalítico Mexicano.

Maya González, José Antonio (2015), “Entre la afección cerebral y la perversión moral. Clínica, terapéutica y criminalización de la epilepsia en la medicina mental de finales del siglo XIX, Ciudad de México", Temas de historia de la psiquiatría argentina, XVIII (34), pp. 40-52.

Moreno, Roberto (1989), La polémica del darwinismo en México: siglo XIX. Testimonios, México, Universidad Nacional Autónoma de México/Instituto de Investigaciones Históricas.

Moretic, Yerko (1975), “Acerca de las raíces ideológicas del modernismo hispanoamericano". En: Litvak, Lily (ed.), El modernismo, Madrid, Taurus, pp. 51-64.

Nouzeilles, Gabriela (2000), Ficciones somáticas: naturalismo, nacionalismo y políticas médicas del cuerpo (Argentina, 1880-1910), Buenos Aires, Beatriz Viterbo.

Piccato, Pablo (2005), “Honor y opinión pública: la moral de los periodistas durante el Porfiriato temprano". En: Sacristán, Cristina; Piccato, Pablo (coords.), Actores, espacios y debates en la historia de la esfera pública en la Ciudad de México, México, Instituto Mora, pp. 145-178.

Quevedo y Zubieta, Salvador (1885), Manuel González y su gobierno. Anticipo a la historia, II, México, Establecimiento Tipográfico Montealegre.

Rama, Ángel (1984), La ciudad letrada, Hanover, Ediciones del Norte.
Ramos Velásquez, Jesús Miguel (2015), “Aquellos son los hombres locos. De los discursos científicos al internamiento en el hospital de San Hipólito, 1886-1890", Trashumante. Revista Americana de Historia Social, 5, pp. 265-288.

Ríos Molina, Andrés (2008), “Locura y encierro psiquiátrico en México: El caso del manicomio La Castañeda, 1910", Antipoda, 6, pp. 74-90.

Ríos Molina, Andrés (2009), La locura durante la Revolución Mexicana. Los primeros años del Manicomio General de La Castañeda, 1910-1920, México, El Colegio de México.

Ríos Molina, Andrés (2016), Cómo prevenir la locura. Psiquiatría e Higiene Mental en México, 1934-1950, México, Siglo XXI/Universidad Nacional Autónoma de México.

Rotker, Susana (1991), Fundación de una escritura: las crónicas de José Martí, La Habana, Casa de Las Américas.

Ruiz, Luis E. (1904), Tratado elemental de higiene, México, Oficina Tipográfica de la Secretaría de Fomento.

Saborit, Antonio (1987), "El regreso de Pedro Castera", Nexos, 116 , pp. 66-73.

Sacristán, Cristina (1998), “¿Quién me metió en el manicomio? El internamiento de enfermos mentales en México, siglos XIX y XX", Relaciones, 4, pp. 203-233.

Sacristán, Cristina (1999), Locura y justicia en México. La psiquiatría, la familia y el individuo frente a la modernidad liberal: el caso Raygosa (1873-1877), (tesis de grado inédita), Tarragona, Universitat Rovira i Virgili.

Sacristán, Cristina (2002), "Entre curar y contener. La psiquiatría mexicana ante el desamparo jurídico, 1870-1944", Frenia. Revista de Historia de la Psiquiatría, II (2), pp. 61-80.

Sacristán, Cristina (2016), “La recepción de la monomanía en los tribunales mexicanos durante la segunda mitad del siglo XIX", texto presentado en el III Coloquio del Seminario Interdisciplinario en Salud Mental. La circulación, recepción y reinterpretación de saberes "psi", siglos XIX-XX.

Sandoval, Adriana (2005), "La Carmen de Pedro Castera", Literatura Mexicana, 16 (1), pp. 7-26.

Schneider, Luis Mario (1987), "Introducción”. En: Castera, Pedro, Las minas y los mineros. Querens, México, Universidad Nacional Autónoma de México, pp. 5-19.

Starobinski, Jean (2016), La tinta de la melancolía, México, Fondo de Cultura Económica.

Villa Guerrero, Guadalupe (2008), “El Hospital del Divino Salvador para mujeres dementes", Boletín de Monumentos Históricos, 12, pp. 141-152.

Zavala Díaz, Ana Laura (2012), De asfódelos y otras flores del mal mexicanas. Reflexiones sobre el cuento modernista de tendencia decadente (1893-1903), México, Universidad Nacional Autónoma de México/Instituto de Investigaciones Filológicas. 